\title{
Arterial oxygenation during one lung ventilation
}

\author{
Tomoaki Shimizu MD, * \\ Kazuo Abe MD, \\ Keiko Kinouchi MD, * \\ Ikuto Yoshiya MD
}

\begin{abstract}
Purpose: To compare the effects of isoflurane and sevoflurane on arterial oxygenation and middle cerebral artery blood flow velocity during one lung ventilation.

Methods: This was a randomized, crossover study in 20 patients undergoing thoracotomy for oesophageal cancer and scheduled for long term one lung ventilation (OLV). They were randomized to one of two groups: group $A$, firstly isoflurane was administered followed by sevoflurane, and then isoflurane was resumed; group $B$, the order of the administration was reversed. Arterial blood gas samples were drawn at the start of OLV. 30 and 60 min after the initiation of OLV and the end of OLV (the change of volatile anesthetics was done 30 and 60 min after the start of OLV). Middle cerebral artery (MCA) was monitored continuously with the probe positioned over the temporal bone window. This probe transmitted $2 \mathrm{MHZ}$ wave Doppler signals. Time-averaged MCA blood flow velocity was calculated from the signals.
\end{abstract}

Results: The $\mathrm{PaO}$, values decreased $30 \mathrm{~min}$ after the start of OLV $(364.4 \pm 33.4 \mathrm{mmHg}$ vs $179.0 \pm 19.5$. and $338.7 \pm 24.8 \mathrm{mmHg}$ vs $139.7 \pm 19.9$ in groups $A$ and $B$ respectively), but there was no difference between the groups. Blood flow velocity of MCA did not change after the start of OLV $(53.1 \pm 3.2,55.9 \pm 3.0,56.4 \pm 2.4$. and 54.1 $\pm 1.9 \mathrm{vs} 50.8 \pm 2.1 .50 .7 \pm 2.4 .53 .7 \pm 1.5,50.8 \pm 2.2 \mathrm{~cm} \cdot \mathrm{sec}^{-1}$ in groups $A$ and $B$ respectively): there was no difference between the groups. $(P<0.05)$.

Conclusion: In clinical practice, the selection of either isoflurane and sevoflurane for OLV was of no difference in terms of the arterial blood oxygenation. With both agents MCA blood flow velocity was maintained during OLV.

Objectif : Comparer les effets de l'isoflurane et du sévoflurane sur l'oxygénation artérielle et la vélocité du débit de l'artère cérébrale moyenne pendant la ventilation unipulmonaire.

Méthodes : Cette étude aléatoire avec croisement regroupait 20 sujets thoracotomisés pour un cancer de l'oesophage et programmés pour une ventilation unipulmonaire (NUP) prolongée. Ils ont été répartis au hasard en deux groupes : le groupe A recevait de lisoflurane suivi du sévoflurane et de lisoflurane à nouveau; dans le groupe B, l'ordre des agents était inversé. Des échantillons de sang étaient prélevés pour la gazométrie artérielle au début de la VUP, 30 et $60 \mathrm{~min}$ plus tard, et à la fin de la VUP (l'échange d'anesthésique volatil survenait 30 et 60 min après l'initiation de la VUP). Un capteur placé sur l'os temporal permettait de monitorer l'artère cérébrale moyenne (ACM) en continu par la transmission d'ondes Doppler de $2 \mathrm{MHZ}$. Ces signaux ont servi au calcul de la moyenne de la vélocité du débit de l'ACM en fonction du temps.

Résultats : Les valeurs de $\mathrm{la} \mathrm{PaO}_{2}$ ont diminué 30 min après le début de la VUP (respectivement dans les groupes $A$ et $B: 364.4 \pm 33.4 \mathrm{mmHg}$ à $179,0 \pm 19,5$ et $338.7 \pm 24.8 \mathrm{mmHg}$ à $139.7 \pm 19,9)$ mais sans différence intergroupe. La vélocité sanguine de l'ACM n'a pas changé après la mise en marche de la VUP (respectivement dans les groupes A et $B: 53.1 \pm 3.2: 55.9 \pm 3.0: 56.4 \pm 2.4$ et $54.1 \pm 1.9$ vs $50.8 \pm 2.1: 50.7 \pm$ $\left.2.4 ; 53.7 \pm 1.5 ; 50.8 \pm 2.2 \mathrm{~cm} \cdot \mathrm{s}^{-1}\right)$ : il n'y a pas eu de différence entre les groupes $(P<0.05)$.

Conclusion : En clinique, le choix de l'isoflurane ou du sévoflurane pour la VUP n'influence pas l'oxygénation artérielle. Le débit sanguin de l'ACM se maintient pendant la VUP avec l'un et l'autre des agents.

From the Department of Anaesthesiology of Osaka University Medical School ${ }^{*}$ Department of Anaesthesiology of Osaka Medical Center and Research Institute for Maternal and Child Health.

Address correspondence to: Kazuo Abe $\mathrm{MD}$, Department of Anaesthesiology, Osaka University Medical School, 2-2 Yamadaoka, Suita, Osaka 565 Japan; Phone: 01 1-81-6-879-3133; Fax: 011-81-6-879-3139.

Accepted for publication Jutly $28,1997$. 
$\mathrm{H}$ YPOXAEMIA during one lung ventilation $(\mathrm{OLV})$ in patients undergoing oesophageal cancer surgery remains a major problem. It has been reported that hypoxaemia occurs in some of these patients. ${ }^{1}$ In order to prevent hypoxaemia during OLV, various measures have been recommended, including the use of high concentrations of oxygen, the application of continuous positive airway pressure (CPAP) to the nonventilated lung, or nitric oxide insufflation. The major cause of the hypoxaemia is intrapulmonary shunting, and hypoxic pulmonary vasoconstriction (HPV) is a compensatory response during OLV. Volatile anaesthetics are commonly used during oesophageal cancer surgery because they are rapid to titrate. However, they have several effects on arterial oxygenation including inhibition of HPV, and this effect is different among the volatile anaesthetics. ${ }^{2-5}$ Therefore, the choice of volatile agent is one of the measures used to avoid hypoxaemia during OLV. A comparison of oxygenation during halothane, enflurane and isoflurane anaesthesia showed that isoflurane was superior to halothane and enflurane. ${ }^{6,7}$

The purpose of this study was to compare arterial oxygenation and cerebral blood flow during OLV with isoflurane and sevoflurane using a randomized crossover design.

\section{Methods and materials}

The investigation was approved by the Committee on Human Studies of Osaka University Hospital and informed consent was obtained from each patient. Twenty patients undergoing thoracotomy for oesophageal cancer and scheduled for more than two hours OLV were enrolled for this study. Patients were randomized to one of two study groups. In group A, isoflurane was administered first followed by sevoflurane; in group B, sevoflurane was administered first followed by isoflurane. On admission to the operating room, patients were placed on a water circulating heating mattress, and an intravenous cannula was inserted under local anaesthesia. A thoracic epidural catheter was positioned for post operative pain relief but no medication was administered until the end of surgery. Anaesthesia was induced with $4 \mathrm{mg} \cdot \mathrm{kg}^{-1}$ thiopentone $i v$, supplemented with $0.1 \mathrm{mg}$ fentanyl and isoflurane $(1-2.5 \%$ inspired) or sevoflurane ( $1-2.5 \%$ inspired). Vecuronium bromide, $0.1 \mathrm{mg} \cdot \mathrm{kg}^{-1}$, was given to facilitate tracheal intubation. After intubation, mechanical ventilation was with a gas mixture of nitrous oxide $50 \%$ in oxygen to maintain $\mathrm{P}_{\mathrm{ET}} \mathrm{CO}_{2}$ at about $35-40 \mathrm{mmHg}$. Anaesthesia was maintained with isoflurane or sevoflurane ( $1-2.5 \%$ inspired). All patients were operated in the left lateral decubitus position. A radial artery catheter was used to aid continuous monitoring of arterial blood pressure as well as arterial blood sampling. Arterial blood was analysed with an automated blood gas analyser (ABL 320 Radiometer Copenhagen). A triple lumen catheter was introduced into the internal jugular vein for central venous pressure monitoring. Additional monitoring for all patients included ECG, pulse oximetry, oesophageal temperature, urine output, neuromuscular blockade and peak airway pressure. End tidal concentration of isoflurane or sevoflurane was monitored using an anaesthetic gas analyser (M1026A Hewlett Packard USA). In group A, isoflurane in oxygen 50\% and nitrous oxide at a concentration sufficient to produce an end-tidal concentration of 1 MAC (1.2\%) was administered. After induction of anaesthesia, a leftsided double lumen endobronchial tube was placed in all patients and initially positioned by auscultation and fibreoptic bronchoscopy.

After turning the patients to the lateral decubitus position, the endobronchial tube position was confirmed with fibreoptic bronchoscopy just before initiation of OLV. Tidal volumes of $10 \mathrm{ml} \cdot \mathrm{kg}^{-1}$ were used during both one- and two lung ventilation (2 LV) with the rate adjusted to maintain $\mathrm{P}_{\mathrm{ET}} \mathrm{CO}_{2}$ between $35-45 \mathrm{mmHg}$.

Middle cerebral artery (MCA) blood flow velocity was monitored continuously. A probe which transmits a 2-MHZ pulsed wave was positioned over the temporal bone window and was fixed to the patient's head with an elastic bandage so that the angle of insonation remained constant during the study. Doppler signals from the MCA were identified and measured at a depth of $50-55 \mathrm{~mm}$. Time-averaged MCA blood flow velocity was calculated from systolic and diastolic velocity using the formula: (systolic velocity-diastolic velocity $/ 3+$ diastolic velocity)

Arterial blood gas samples were drawn during $2 \mathrm{LV}$ immediately before the initiation of OLV and then 30 min after the start of OLV. In group A, isoflurane was then discontinued and replaced with sevoflurane titrated to maintain an end-tidal concentration of sevoflurane $1 \mathrm{MAC}(1.7 \%)$. After the $30 \mathrm{~min}$, arterial blood samples were drawn, sevoflurane was discontinued and isoflurane was resumed. Arterial blood samples were drawn at the end of OLV. For group B patients, the protocol was identical except that the order of isoflurane and sevoflurane administration was reversed (Figure 1). Systolic arterial blood pressure (SABP), diastolic arterial blood pressure (DABP), central venous pressure (CVP) were measured during study periods.

Results are expressed as mean \pm SEM. The effects of anaesthetic on arterial blood gas and haemodynamic 


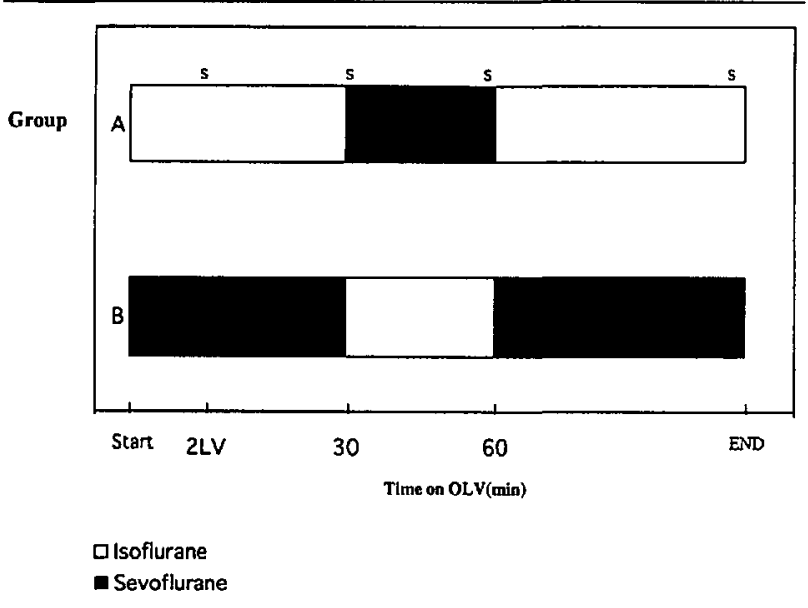

FIGURE 1 Order of administration of each volatile anaesthetic and arterial blood sampling periods. $2 \mathrm{LV}$ : end period of two lung ventilation; s: period of arterial blood sampling; END: end period of one lung ventilation.

variables as well as MCABFV during sevoflurane or isoflurane anaesthesia were compared using multivariable repeated measures ANOVA, and Bonferroni correction. In all tests, the level of significance was set at $\mathbf{5 \%}$.

\section{Results}

Twenty patients ( 16 male and 4 female) were enrolled in this study. Radical surgery was performed in all. Comparison of age, height, body weight, duration of anaesthesia before OLV, and the total duration of OLV were not different between groups. The values for $\mathrm{SABP}, \mathrm{DABP}, \mathrm{CVP}, \mathrm{pH}, \mathrm{PO}_{2}, \mathrm{PCO}_{2}$ and $\mathrm{MCABFV}$ are shown in Table I. The SABP, DABP, HR and CVP did not change during the study. The $\mathrm{PaO}_{2}$ values decreased at $30 \mathrm{~min}$ after the start of $\operatorname{OLV}(364.4 \pm$ $33.4 \mathrm{mmHg}$ os $179.0 \pm 19.5 \mathrm{mmHg}, 338.7 \pm 24.8$ $\mathrm{mmHg}$ ps $139.7 \pm 19.9 \mathrm{mmHg}$; group $\mathrm{A}$ and group $\mathrm{B}$ respectively). There was no difference in $\mathrm{PaO}_{2}$ between isoflurane and sevoflurane during OLV (Figure 2). Blood flow velocity of MCA did not change after the starting of OLV with either anaesthetic $(53.1 \pm 3.2$, $55.9 \pm 3.0,56.4 \pm 2.4$, and 54.11 .9 vs $50.8 \pm 2.1,50.7$ $\pm 2.4,53.71 .5$, and $50.8 \pm 2.2 \mathrm{~cm} \cdot \mathrm{sec}^{-1}$ in groups $A$ and $B$ respectively) (Figure 3 ).

\section{Discussion}

The purpose of this study was to determine whether there was a difference between two commonly used volatile anaesthetics with regard to arterial oxygenation and MCA blood flow velocity during OLV. No differences between isoflurane and sevoflurane were detected.

Oxygenation during OLV is influenced by factors such as hypoxic pulmonary vasoconstriction in the nonventilated lung and the alveolar pressure in the ventilated lung. Measures to prevent arterial oxygen desaturation during OLV include the use of $100 \% \mathrm{O}_{2}$, the application of continuous positive airway pressure $(\mathrm{CPAP}),{ }^{8}$ repeated inflation of the nonventilated lung ${ }^{9}$ application of positive end expiratory pressure

TABLE I Haemodynamic data.

\begin{tabular}{|c|c|c|c|c|}
\hline Group $A$ & pre $(2 L V)$ & Iso $(30 \mathrm{~min})$ & $\operatorname{Sev}(60 \mathrm{~min})$ & $E N D$ \\
\hline $\begin{array}{l}\mathrm{SABP}(\mathrm{mmHg}) \\
\mathrm{DABP}(\mathrm{mmHg}) \\
\mathrm{HR}(\mathrm{bpm}) \\
\mathrm{CVP}(\mathrm{mmHg}) \\
\text { pH } \\
\mathrm{PO}_{2}(\mathrm{mmHg}) \\
\mathrm{PCO}_{2}(\mathrm{mmHg}) \\
\mathrm{MCABFV}\left(\mathrm{cm} \cdot \mathrm{sec}^{-1}\right)\end{array}$ & $\begin{array}{l}123.7 \pm 8.1 \\
70.8 \pm 5.3 \\
82.9 \pm 6.7 \\
10.5 \pm 0.8 \\
7.42 \pm 0.24 \\
364.4 \pm 33.4 \\
37.4 \pm 1.8 \\
53.1 \pm 3.2\end{array}$ & $\begin{array}{l}119.0 \pm 5.4 \\
66.6 \pm 2.6 \\
81.9 \pm 4.4 \\
10.5 \pm 0.5 \\
7.36 \pm 0.25 \\
179.0 \pm 19.5 * \\
42.1 \pm 1.6 \\
55.9 \pm 3.0\end{array}$ & $\begin{array}{l}122.7 \pm 4.3 \\
72.8 \pm 3.5 \\
85.7 \pm 3.3 \\
10.4 \pm 0.5 \\
7.37 \pm 0.27 \\
150.8 \pm 9.7^{\star} \\
43.2 \pm 1.9 \\
56.4 \pm 2.4\end{array}$ & $\begin{array}{l}120.1 \pm 5.7 \\
60.3 \pm 3.4 \\
78.7 \pm 3.6 \\
9.3 \pm 0.4 \\
7.37 \pm 0.02 \\
173.1 \pm 20.7^{\star} \\
42.2 \pm 1.2 \\
54.1 \pm 1.9\end{array}$ \\
\hline Group B & pre $(2 L V)$ & $\operatorname{Sev}(30 \mathrm{~min})$ & Iso (60 min) & $E N D$ \\
\hline $\begin{array}{l}\text { SABP }(\mathrm{mmHg}) \\
\text { DABP }(\mathrm{mmHg}) \\
\mathrm{HR}(\mathrm{bpm}) \\
\mathrm{CVP}(\mathrm{mmHg}) \\
\mathrm{pH} \\
\mathrm{PO}_{2}(\mathrm{mmHg}) \\
\mathrm{PaCO}_{2}(\mathrm{mmHg}) \\
\mathrm{MCABFV}\left(\mathrm{cm} \cdot \mathrm{sec}^{-1}\right)\end{array}$ & $\begin{array}{l}114.8 \pm 6.4 \\
62.8 \pm 4.2 \\
87.6 \pm 5.3 \\
7.9 \pm 0.8 \\
7.42 \pm 0.01 \\
338.7 \pm 24.8 \\
39.8 \pm 0.8 \\
50.8 \pm 2.1\end{array}$ & $\begin{array}{l}110.8 \pm 6.3 \\
63.2 \pm 3.9 \\
93.6 \pm 8.3 \\
8.1 \pm 0.8 \\
7.40 \pm 0.10 \\
139.7 \pm 19.9 \\
40.9 \pm 1.8 \\
50.7 \pm 2.4\end{array}$ & $\begin{array}{l}107.5 \pm 6.7 \\
66.6 \pm 3.5 \\
98.0 \pm 6.6 \\
8.4 \pm 0.9 \\
7.38 \pm 0.01 \\
134.6 \pm 16.7^{\star} \\
39.5 \pm 1.8 \\
53.7 \pm 1.5\end{array}$ & $\begin{array}{l}105.8 \pm 7.3 \\
60.8 \pm 3.3 \\
92.6 \pm 6.9 \\
7.5 \pm 0.9 \\
7.38 \pm 0.01 \\
148.0 \pm 22.7^{\star} \\
39.5 \pm 1.4 \\
50.8 \pm 2.2\end{array}$ \\
\hline
\end{tabular}

mean \pm sem

$\rightarrow P<0.05$ compared with prevalue $(2 \mathrm{LV})$

SABP: systolic arterial blood pressure, DABP: diastolic arterial blood pressure, HR: heart rate, CVP: central venous pressure,

MCABFV: middle cerebral artery blood flow velocity. $2 \mathrm{LV}: 2$ lung ventilation. 


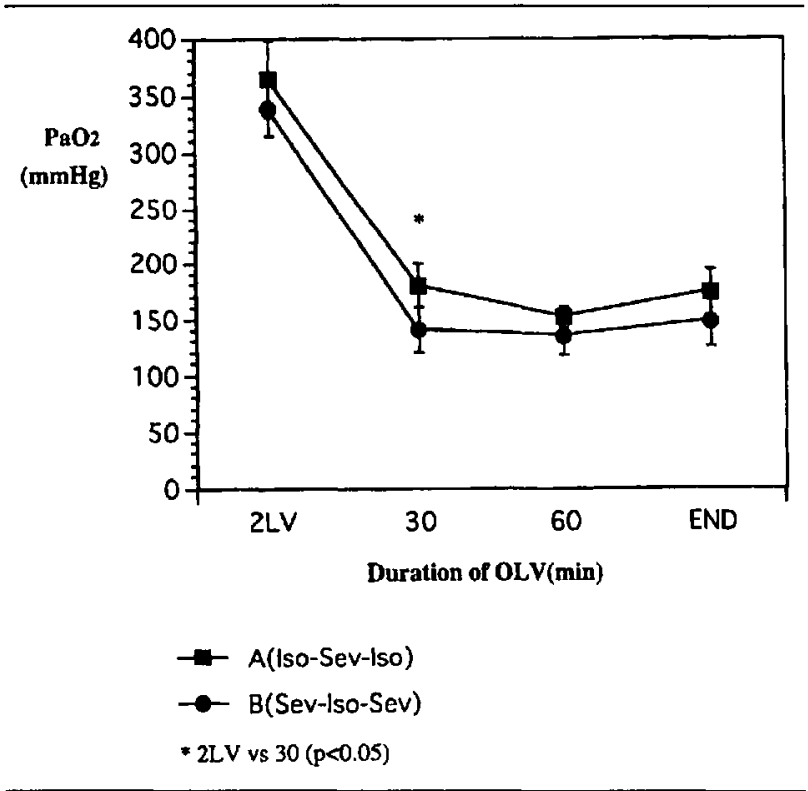

FIGURE 2 Arterial blood oxygenation pressure (mean \pm SEM) ps time during OLV. $\mathrm{PaO}_{2}$ : arterial blood oxygen pressure; $2 \mathrm{LV}$ : end period of two lung ventilation; OLV: one lung ventilation; END: end period of one lung ventilation.

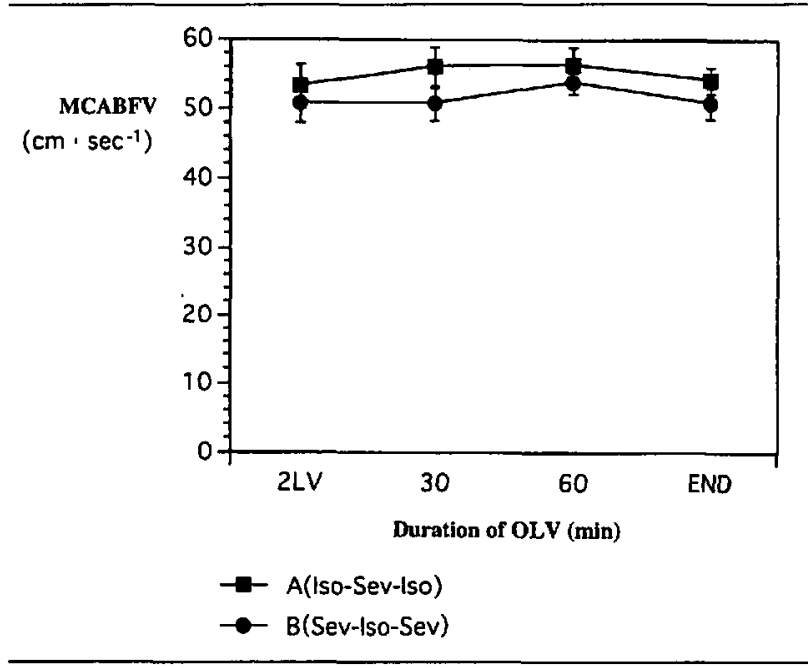

FIGURE 3 MCA blood flow velocity (mean \pm SE) versus time during OLV. MCABFV: middle cerebral artery blood flow velocity; 2LV: end period of two lung ventilation; OLV: one lung ventilation; END: end period of one lung ventilation

(PEEP), and manipulation of the tidal volume in the ventilated lung. ${ }^{10}$ In addition, several management options, including the choice of anaesthetic agent, could influence the $\mathrm{PaO}_{2}$ during OLV. The effects of several anaesthetic agents on arterial oxygenation during OLV have been compared previously. ${ }^{6,10-12}$ Volatile anaesthetics have been reported to decrease arterial blood oxygenation through an inhibitory effect on HPV. ${ }^{2-5,13,14}$ In human studies, halothane is associated with lower mean $\mathrm{PaO}_{2}$ during OLV than during intravenous anaesthesia. Volatile anaesthetics, especially isoflurane and sevoflurane are commonly used for maintenance of anaesthesia during OLV. Slinger et al. compared the effect of isoflurane and enflurane on oxygenation during OLV in 28 patients who had prolonged periods of OLV in a cross over design, and reported that $\mathrm{PaO}_{2}$ after $30 \mathrm{~min}$ isoflurane or enflurane anaesthesia during OLV were $231 \pm 125$ $\mathrm{mmHg}$ vs $184 \pm 106 \mathrm{mmHg}{ }^{6}$ Ishibe et al. reported that sevoflurane inhibited hypoxic pulmonary vasoconstriction with a potency similar to that of isoflurane in the perfused rabbit lung. ${ }^{3}$ The half- inhibition value $\left(\mathrm{ED}_{50}\right)$ of $\mathrm{HPV}$ with isoflurane and sevoflurane were $0.85 \pm 0.22 \mathrm{MAC}$ and $1.00 \pm 0.12 \mathrm{MAC}$, respectively. Fujita $t$ t al. examined the effects of sevoflurane on oxygenation and haemodynamic valuables in animals. ${ }^{15}$ They concluded that, although sevoflurane caused a dose-dependent depression of right ventricular function, it can be safely used during OLV. We compared the effects on oxygenation of isoflurane or sevoflurane in humans. The $\mathrm{PaO}_{2}$ decreased after the start of OLV with both anaesthetics, but there were no differences in oxygenation between isoflurane and sevoflurane. We conclude that isoflurane and sevoflurane can be used safely during OLV and that the choice between them is not important in terms of arterial blood oxygenation.

Hypoxaemia during anaesthesia can cause severe organ damage, particularly to the brain. During OLV, a decrease of $\mathrm{PaO}_{2}$ is inevitable, and it may be severe. ${ }^{1}$ In this study, we used a non-invasive Doppler wave transmitter to monitor MCA blood flow velocity. Monitoring regional blood flow is a method that may evaluate oxygenation of each organs. The MCA blood flow velocity did not change after the start of OLV with either anaesthetic and there were no differences between isoflurane and sevoflurane. We conclude that, in clinical practice, isoflurane and sevoflurane maintain MCA blood flow velocity during OLV.

\section{References}

1 Barker SJ, Clarke C, Tirvedi N, Hyatt J, Fynes $M$, Roessler $P$. Anesthesia for thoracoscopic laser ablation of bullous emphysema. Anesthesiology 1993; 78: 44-50.

2 Carlsson AJ, Bindslev L, Hedenstierna G. Hypoxiainduced pulmonary vasoconstriction in the human lung. The effect of isoflurane anesthesia. Anesthesiology $1987 ; 66: 312-6$. 
3 Ishibe $\Upsilon$, GuiX, Uno $H$, Shiokawa $\Upsilon$, Umeda $T$,

Suekane $K$. Effect of seveflurane on hypoxic pulmonary vasoconstriction in the perfused rabbit lung. Anesthesiology 1993; 79: 1348-53.

4 Loer SA, Scheeren TWL, Tarnow J. Desflurane inhibits hypoxic pulmonary vasoconstriction in isolated rabbit lungs. Anesthesiology 1995; 83: 552-6.

5 Uno $H$, Ishibe $\Upsilon$, Umeda $T$, et al. Evaluation of inhibitory effect of isoflurane on the hypoxic pulmonary vasoconstriction response in dogs. (Japanese) Masui 1994; 43: 1288-96.

6 Slinger P, Scott WAC. Arterial oxygenation during onelung ventilation. A comparison of enflurane and isoflurane. Anesthesiology 1995; 82: 940-6.

7 Marshall C, Lindgren L, Marshall B. Effects of halothane, enflurane, and isoflurane on hypoxic pulmonary vasoconstriction in rat lungs in vitro. Anesthesiology 1984; 60: 304-8.

8 Capan LM, Turndorf $H$, Patel C, Ramanathan $S$, Acinapura $A$, Chalon J. Optimization of arterial oxygenation during one-lung anesthesia. Anesth Analg 1980; 59: 847-51.

9 Malmkvist $G$. Maintenance of oxygenation during onelung ventilation. Effect of intermittent reinflation of the collapsed lung with oxygen. Anesth Analg 1989; 68: 763-6.

10 Katz JA, Laverne RG, Fairley HB, Thomas AN. Pulmonary oxygen exchange during endobronchial anesthesia: effect of tidal volume and PEEP. Anesthesiology 1982; 56: 164-71.

11 Benumof JL, Augustine SD, Gibbons JA. Halothane and isoflurane only slightly impair arterial oxygenation during one-lung ventilation in patients undergoing thoracostomy. Anesthesiology 1987; 67: 910-5.

12 Rogers $S N$, Benumof $\pi$. Halothane and isoflurane do not decrease $\mathrm{PaO}_{2}$ during one-lung ventilation in intravenously anesthetized patients. Anesth Analg 1985; 64: 946-54.

13 Groh J, Kubnle GEH, Sckell A, Ney L, Goetz AE. Isoflurane inhibits hypoxic pulmonary vasoconstriction: an in vivo fluorescence microscopic study in rabbits. Anesthesiology 1994; 81: 1436-44.

14 Grob J, Kubnle GEH, Ney L, Sckell A, Goetz AE. Effects of isoflurane on regional pulmonary blood flow during one-lung ventilation. $\mathrm{Br} J$ Anaesth 1995; 74: 209-16.

15 Fujita $\Upsilon$, Tamasaki $T$, Takaori $M$, Sekioka $K$. Sevoflurane anaesthesia for one-lung ventilation with PEEP to the dependent lung in sheep: effects on right ventricular function and oxygenation. Can J Anaesth 1993; 40: 1195-200. 